\title{
General practice needs ongoing commitment to training budgets
}

\author{
Catherine A O'Donnell chair of the Society for Academic Primary Care (SAPC) and professor of \\ primary care research and development ${ }^{1}$, Joe Rosenthal co-chair, SAPC heads of teaching group ${ }^{2}$, \\ Michael Moore chair, SAPC heads of department group ${ }^{3}$, Nick Francis secretary, SAPC heads of \\ department group ${ }^{4}$, Debbie Sharp professor of primary healthcare ${ }^{5}$, Roger Jones editor ${ }^{6}$, Christian \\ Mallen professor of general practice ${ }^{7}$, John Campbell professor of general practice and primary \\ care $^{8}$
}

${ }^{1}$ General Practice and Primary Care, University of Glasgow, Institute of Health and Wellbeing, Glasgow G12 9LX, UK; ${ }^{2}$ University College London, London, UK; ${ }^{3}$ University of Southampton, Southampton, UK; ${ }^{4}$ Cardiff University, Cardiff, UK; ${ }^{5}$ University of Bristol, Bristol, UK; ${ }^{6}$ British Journal of General Practice, London, UK; ${ }^{7}$ University of Keele, Keele, UK; ${ }^{8}$ University of Exeter, Exeter, UK

The NHS is a key election issue. ${ }^{1}$ Patient demand for primary care rose by $10.5 \%$ between 2007 and $2014,{ }^{2}$ while recruiting and retaining GPs is ever more challenging. The Royal College of General Practitioners' election manifesto for NHS England includes a call to meet the health secretary's pledge of an additional 5000 GPs by 2020 and to increase GPs' training to at least four years to ensure that they have the skills to deal with a patient population with increasingly complex needs. ${ }^{3}$ We are, therefore, deeply concerned that Health Education England has announced plans to cut the educational support budget for GP training by $30 \%$ from next year. ${ }^{4}$

Further cuts seem likely that will seriously affect the ability of medical schools and deaneries to train the GPs of today and tomorrow. Such reductions in funding are clearly at odds with the commitment to increase GP numbers.

As representatives of academic primary care, we are also concerned by the inevitable negative effect of these cuts on the recruitment of GP educators and researchers. The recent report from the Medical Schools Council and Health Education England emphasised the essential role of primary care educators and academics in encouraging medical students to make general practice their career choice. ${ }^{5}$ The international standing of primary care research in the UK relies on new and committed
GPs, drawn from a strong pool of practising GPs. Such dramatic disinvestment in GP training will further undermine confidence in general practice as a career for young doctors and medical students and will serve only to deepen the current crisis in general practice.

Competing interests: No competing interests

Full response at: http://www.bmj.com/content/357/bmj.j2024/rr.

1 Page B. What role will the NHS play in the 2017 election?BMJ 2017;357:j2024. doi:10 1136/bmj.j2024 pmid:28450308.

2 Hobbs FDR, Bankhead C, Mukhtar T, et al. National Institute for Health Research School for Primary Care Research. Clinical workload in UK primary care: a retrospective analysis of 100 million consultations in England, 2007-14. Lancet 2016;357:2323-30. doi:10.1016/ S0140-6736(16)00620-6. pmid:27059888.

3 Royal College of General Practitioners. Six steps for safer general practice. 2017. http:// www.rcgp.org.uk/campaign-home.aspx.

4 Kaffash J. GP training set for swingeing cuts as education bosses told to find $30 \%$ savings [article]. Pulse 2017 http://www.pulsetoday.co.uk/your-practice/practice-topics/education/ gp-training-set-for-swingeing-cuts-as-education-bosses-told-to-find-30-savings/20033945 article.

5 Medical Schools Council, NHS Health Education England. By choice-not by chance. Supporting medical students towards future careers in general practice. 2016. https:// www.hee.nhs.uk/sites/default/files/documents/By\%20choice\%20not\%20by\%20chance\% 20web\%20FINAL.pdf.

Published by the BMJ Publishing Group Limited. For permission to use (where not already granted under a licence) please go to http://group.bmj.com/group/rights-licensing/ permissions 